culties and problems of such control encountered in the past. The thermostat will stabilize the temperature of the cold junction to an extent that variations will not exceed $0 \cdot 1$ deg. C. There are therefore no temperature changes to note, nor is ice or liquid required. The instrument is arranged normally to be set to a temperature in the range $42-48^{\circ}$ C., and takes about forty-five minutes to reach stable conditions after switching on.

The needs of the chemist have not been neglected: instruments are now available which will give a continuous indication of the $p H$ of any given liquid under examination, so that rapidly changing conditions may be followed without difficulty. These meters are automatic in operation and can be used in conjunction with a recorder to provide permanent records. Also for the chemist is the conductivity controller: electrolytic conductance measurements afford a convenient and sensitive method for determining a number of factors of basic importance in industrial processes, and the usefulness of such measurements is greatly increased when they are applied to the automatic control of the process being monitored. The instrument shown consisted of a modified Wheatstone bridge network operated at a frequency of $2.9 \mathrm{kc} . / \mathrm{s} .$, and incorporated an amplifier and relay circuit which enable electrical process control to be effected.

Examples of various miniature circuit units were to be seen at the exhibition. Silver conductors are screen-printed and fired, and resistors are formed with a series of baked-on graphite dispersions. The range of resistivities is from $10 \mathrm{ohms}$ to $1 \mathrm{megohm}$ per square, and one type of dispersion will withstand a temperature of $200^{\circ} \mathrm{C}$. for one hour with no more than 1 per cent change in resistance. The resistor noise is of the same low order as that of grade-1 resistors (cracked hydrocarbon type). Ceramic capacitor tablets covering the range $1-10,000 \mu \mu \mathrm{F}$. per unit are available.

The exhibition showed that British instrument makers are keeping abreast of the times, and, in all fields of instrumentation where electronics can play a useful part, it is evident that the user may continue to expect to have new tools placed at his disposal.

J. A. Saxton

\section{MEDICAL RESEARCH COUNCIL}

\section{REPORT FOR THE YEAR 1950-51}

$\mathrm{T}$

HE report of the Medical Research Council for the Year 1950-51* follows the policy of the Council, initiated in the preceding report, of giving, not a complete picture of all that the Council is doing, but a selective account of its activities which discusses the most important work in progress, together with discussions of particular trends of the Council's activities. The report also contains a single classified list of papers published by the Council's individual research workers, an outline of the Council's research programme and the research programmes of each of its many Departments, and lists of the personnel of each of these Departments. An appendix to the report for this year gives in full the text of the

* Committee of Privy Council for Medical Research : Report of the Medical Research Council for the Year 1950-51. (Cmd. 8584.) Pp
iv +214. (London: H.M.S.O., 1952.) 68. net. memorandum on the future organization of medical research, submitted to Parliament in 1918 by the late Viscount Addison, a memorandum which placed the Medical Research Council under the authority, not of the Ministry of Health, but of a Committee of the Privy Council. Anyone who wishes to understand Viscount Addison's reasons for this wise move will find them here explained. Another section of the report pays tribute to the considerable labours of Viscount Addison on behalf of British medicine.

The particular trend of the Council's work that is discussed in the report is "The Training of Research Workers". The discussion of this important subject recognizes that the main responsibility for training these workers rests on the universities, with which the Council has always been closely associated. Agreeing with the late Sir Charles Sherrington that the best way to get scientific fruit is to cultivate the tree, the Council has from the first given grants to support research assistants in university and other departments and has helped to provide opportunities for the training of junior workers in the research of their own establishments. Recently the Council has increased facilities for research workers. It believes that by far the best training for them is actual investigation under the guidance of an expert, and a flexible scheme for the assistance of the training in research has been devised. This scheme is intended to meet individual needs, and there are three main aspects of it : research scholarships (formerly called student ships), clinical fellowships and travelling fellowships.

Postgraduate scholarships are intended for those who have graduated recently in medicine or science, although they include also arrangements for more senior workers, and supplement opportunities provided by the universities. They are available for workers training in any branch of medical science and are awarded for one year, being renewable for a maximum of three years. This scheme began in 1944, and 221 scholarships have so far been awarded. More than half of them have been for subjects allied to chemistry, and a quarter have gone to workers interested in the preclinical subjects.

The clinical fellowships are intended for more senior workers and were created because postgraduate studentships (scholarships) attracted few medical graduates to careers in clinical research. The stipend is that of a registrar in the National Health Service, and they carry continuation of the superannuation provided by departments of health. Provision is also made for any non-clinical work that may be necessary. Any academic or hospital department sponsoring an applicant is required to undertake to give the applicant an opportunity to return to that department if he desires to do so.

The Council has five groups of travelling fellowships at its disposal: Rockefeller fellowships in medicine, Eli Lilly research fellowships in medicine, Dorothy Temple Cross fellowships in tuberculosis, Alexander Pigott Wernher Memorial Trust fellowships in ophthalmology and otology, and French exchange scholarships in medical science. The first two groups are available to workers in clinical and non-clinical subjects, the third and fourth in the special subjects stated, and the fifth in non-clinical subjects only. All are normally tenable for one year. The report describes these fellowships and gives a table that summarizes the careers of those who have held them in the past. 
The selective account of the Council's work entitled "Some Aspects of Medical Research" is, like the similar section in the preceding report, a valuable discussion of modern knowledge of the following subjects : research on proteins, the preservation of spermatozoa and other cells at low temperatures, statistics in medical research, whooping cough, tuberculosis, antibiotics, diseases of the eye and skin, the experimental study of human skilled performance, climatological medicine, cortisone and adrenocorticotropic hormone, malaria, and insecticides. It is impossible, in the space available in this article, to do more than indicate in this way the scope of this interesting section. It does not cover, and it is not intended to cover, the full extent of the Council's activities and interests, the breadth of which is realized only by a study of the research programmes of the Council's numerous departments.

The reports of the Medical Research Council, and also those of kindred organizations, reveal the noble uses to which scientific work is actually being put. Not only is science daily saving the lives and mitigating the suffering of human beings and animals; it is also extending the span of life, fitting it to the demands of modern eivilization and preparing for later generations a better and a healthier world. There is much in the history and literature of the world to remind one of man's desire to help his fellows and other living things; but readers of the reports of the Medical Research Council may well ask themselves where else, outside unpretentious documents such as these, a man may find a comparable record of human labour entirely devoted to the welfare of mankind.

G. LAPAGE

\section{PHOTOGRAPHY IN RESEARCH AT THE UNIVERSITY}

$\mathrm{O}^{\mathrm{N}}$ $\mathrm{N}$ October 4 nearly two hundred people gathered at the Zoology School, Cambridge, to hear a series of short papers on the applications of photography to research in the university. This very successful all-day symposium was organized by the Scientific and Technical Group of the Royal Photographic Society and made possible largely through the enthusiastic co-operation of a number of Cambridge workers, including Prof. J. Gray, Dr. R. H. J. Brown, Mr. A. M. P. Brookes, Mr. Fairfax-Fozzard and Dr. J. S. Courtney-Pratt.

Mr. V. Gallafent opened the symposium by outlining the aims and objects of the Scientific and Technical Group in the advancement of photography. The Second World War, and its after-effects, have prevented the Group from acting on its agreed policy of fostering subsections in the provincial centres. The present meeting at Cambridge marked the first real step towards the realization of this policy; and it was clear that it was a popular one.

A résumé of photographic reciprocity failure by Dr. W. F. Berg led to an interesting discussion on the merits of latensification by a long, low-intensity exposure after the short camera exposure. Mr. G. S. Moore urged, from the floor, that full development in a low-contrast metol developer would give as much speed as could be achieved by latensification, but possibly the latter process gives finer grain at a given $\gamma$ (which defines contrast in the image).

In a very clear paper, Mr. A. M. P. Brookes presented what might best be called a system of approach to any problem in high-speed photography as applied to engineering. It is usual to decide the exposuretime first. Still and ciné techniques differ inasmuch as the shutter-speed for a photograph destined to be examined as a still needs to be shorter than that for a ciné frame, where slight blurring helps to produce a jerk-free movement on projection. Mr. Brookes showed a graph from which the exposure-time could be read off against subject-speed after allowing for scaling-down in the camera. The graph was based on a $0 \cdot 1-\mathrm{mm}$. movement of image on the emulsion. For illumination of the subject, counting the light output from a photoflood as 1, a studio light would be 10, a high-intensity mercury are 50, a flashbulb 1,000 , and a discharge tube 10,000 .

Dr. R. H. J. Brown, of the Department of Zoology, Cambridge, was principally interested in the study of animal movements-the flexure of a pigeon's wings, fish swimming, etc. He dealt, in his paper, mainly with the problems of illumination. For microcinematography the BTH type $F A 5$ lamp having a source $4.5 \mathrm{~mm}$. in length is very good. It can be run continuously at $125 \mathrm{~W}$. or flashed at a rate equivalent to $3 \frac{1}{2} \mathrm{~kW}$.

Mr. H. S. L. Harris described experimental difficulties in connexion with the bringing into operation of a mercury-vapour flash-tube for the photoelastic study of the stressing of gear teeth while running under load.

In the afternoon session Mr. R. G. Horner read a short paper on the limitations of colour photography in the recording of colour. Colour photography is sold to the public in order to give pleasing pictures, and it was never intended as a simple short-cut to colorimetry. When used for recording colours, it is necessary to apply all the standard photometric techniques used in photographic photometry.

A particularly interesting paper was presented by Prof. J. S. Mitchell (professor of radiotherapeutics in the University of Cambridge) dealing with ultraviolet and fluorescence photography, particularly that of cancerous tumours. Work is in progress on the relation between the disturbance of cellular nucleic acid metabolism (as revealed by ultra-violet absorption) and the production of structural changes in chromosomes by the therapeutic doses of irradiation.

Animal experiments have confirmed the increased fluorescence to ultra-violet light of the actively growing parts of the tumour and some other tissues following the injection of tracers. Prof. Mitchell appealed for guidance in colour-photographing the yellow fluorescence of the dissected tissues so as to yield quantitative results. A similar appeal was made by Dr. K. W. Rizk, who is engaged in recording the flow patterns that occur when water containing a blue indicator (such as litmus) is injected into a tank containing a colourless solution that turns the indicator red. Dr. Rizk was disappointed to find that the boundary between the blue central cone of the jet and the red mantle varied according to the camera exposure. No help was forthcoming from the meeting for Prof. Mitchell or Dr. Rizk beyond a re-emphasis of the limitations of commercial colourprocesses.

In the section on radiation microscopy, Dr. V. E. Cosslett (Cavendish Laboratory) considered the suitability of photographic materials for electron and X-ray work. For ordinary work the available materials are satisfactory, but for some purposes it would be advantageous to have specially improved materials. Dr. Cosslett appealed for more work to 